\title{
Role of Adaptive Home Based Workspaces in Coping Gender Inequality in Korail Slum, Dhaka
}

\author{
Iftekhar Ahmed \\ Department of Architecture, BRAC University, Bangladesh
}

Copyright $\bigcirc 2017$ by authors, all rights reserved. Authors agree that this article remains permanently open access under the terms of the Creative Commons Attribution License 4.0 International License

\begin{abstract}
Gender and the politics of space are closely interrelated. Like many other sprawling cities, in Dhaka slums are the natural consequence of rapid, unplanned urbanization and poor economic growth. Due to extreme poverty and lower level of education, the female slum dwellers face acute gender inequality. The study investigates how women facing gender inequality use home based work as coping mechanism. The study attempts to identify the adaptive micro-scale workspaces and their role in everyday life of female slum dwellers. To explore this and related issues, the study uses interviews, focus group discussion and observation as research tools in Korail slum of Dhaka. Key findings of the study are the pattern of spontaneous cultural adaptations and female workers' ability to create home based workspaces for survival. These will potentially contribute in identifying the spontaneous micro-scale space typologies in adapted gendered spaces. Establishing this facilitates the understanding of their role as coping mechanism against gender inequality, which can guide possible future intervention and/or external support.
\end{abstract}

Keywords Home Based Work, Slum, Gender Inequality, Adaptive Micro Scale Spaces, Female Workers

\section{Introduction}

The Asia/Near East Region (ANE) contains $60 \%$ of the world's slums, which in absolute numbers represents about 550 million slum dwellers [1]. It is expected that if the situation remains same, the number will probably double by 2030. Categorical terms like a slum, can disguise significant cultural and economic distinctions among low-income settlements. Variously known as informal or non-formal cities, squatter settlements, or shantytowns, these communities differ dramatically in size, character, age, and level of political and social organization [2]. However, few characteristics remain common: separate from urban infrastructures such as roads, sewers, transportation, water and electricity supply, and storm-water management; having severe health, environmental, security problems and lack of public facilities such as cultural, economic or recreational activities.

About one third of the population of Bangladesh lives in urban areas (Table 1). Dhaka, a megacity of 15.4 million [3] people and capital of Bangladesh has a high concentration of slums in the greater urban area which encompasses approximately 1,530 square $\mathrm{km}$ [4]. This is a consequence of rapid, unplanned urbanization and poor political and economic decisions. For the past two decades, Dhaka has been experiencing a rapid population growth much higher than the rest of the country (Table 1). Dhaka's population grew exponentially over the past four decades due to gradual changes in demographic, economic and social fabric. A more specific source is migrants from over populated rural areas; often victims of natural calamities, landlessness and poverty. Annually, the city draws an estimated 300,000 to 400,000 mostly poor migrants who provide critical employment for the city's industries and services. Roy and Sarker [5] observes: "Although urbanization is often associated with increasing national production and high per capita GDP, poverty remains a persistent feature of the urban life, both in terms of income and living conditions". The economic growth has failed to keep up the same pace mainly due to poor political decisions. According to Bangladesh Bureau of Statistics (BBS), the yearly per capita income of Bangladesh is $\$ 1,314$ as in 2015 [6]. In 2014, of the 15.4 million people of Dhaka city [7], up to $6.9 \%$ was living in the slums [8]. 
Table 1. Growth of national and urban population (Million) in Bangladesh, 2000-2015, Source: [9]

\begin{tabular}{|c|c|c|c|c|c|c|}
\hline Year & $\begin{array}{c}\text { Total National } \\
\text { Population } \\
\text { (Million) }\end{array}$ & $\begin{array}{c}\text { Annual growth rate } \\
\text { of national } \\
\text { Population (\%) }\end{array}$ & $\begin{array}{c}\text { Total urban } \\
\text { Population } \\
\text { (Million) }\end{array}$ & $\begin{array}{c}\text { Urban Population as \% of total } \\
\text { Population (level of urbanization) }\end{array}$ & $\begin{array}{c}\text { Density } \\
(\mathrm{P} / \mathrm{Sq} \text { km) }\end{array}$ & $\begin{array}{c}\text { Migrants } \\
(\mathrm{net})\end{array}$ \\
\hline 2000 & 132.38 & 2.01 & 31.23 & 24 & 1,114 & $-151,224$ \\
\hline 2005 & 143.14 & 1.57 & 36.69 & 26 & 1,101 & $-400,001$ \\
\hline 2010 & 151.13 & 1.09 & 42.15 & 28 & 1,049 & $-714,191$ \\
\hline 2014 & 158.51 & 1.22 & 47.33 & 30 & 994 & $-456,443$ \\
\hline 2015 & 160.41 & 1.20 & 48.72 & 30 & 919 & $-408,112$ \\
\hline
\end{tabular}

Slums are the natural consequence of rapid, unplanned urbanization and poor economic growth. They are directly linked to housing condition of a city, often showing the failures of the sector. Housing is widely regarded as an essential human need and right, as reflected in its incorporation into the Millennium Development Goals (MDG). MDG 7, Target D states that, "Achieve, by 2020, a significant improvement in the lives of at least 100 million slum dwellers" [10]. As most slums are developed illegally, the government, NGOs and donors generally do not provide basic services such as water, sanitation, electricity, health and education in these areas. Also, close to 80 percent of slums are located on privately owned land, creating considerable institutional challenges in terms of basic service provision [11]. There are between 16 to 40 different bodies involved in one way or another in urban matters in Dhaka with little coordination and planning [11]. As a result, there are major gaps in provision of services and infrastructure.

There are about 100 million home based workers worldwide; of them 50 million in South Asia, of whom 80 percent are women [23]. It has been recognized that space and the built environment are constituted by, as well as constitutive of gender, in feminist analyses of the city, even if the 'private' space of the household has tended to be somewhat neglected in mainstream theory $[11,14]$. Space and built environment are closely related to local culture and gender dynamics in a society. For example, the meaning of a private space varies widely across different cultures. This has direct implications for female home based workers worldwide.

In developing countries, women lag behind socially, economically and politically even though in most cases, they are demographically superior in urban areas. This is reflected in the widespread gender gap in the acquisition of 'human capital' such as education, and vocational skills and training. The problem is more acute among the slum dwellers where gender-equitable access to 'decent' work and living environments is nearly absent. Gendered spaces play an important role in balancing this, albeit in a limited capacity.

\subsection{Objectives}

The objective of this study is to examine the underexplored adaptive micro-scale work environments in slums of Dhaka with a focus on how they help in coping gender inequality through home based work. In recent years, there have been significant economic, social and political developments for women that came with rapid urbanization. Yet, gender inequality for female slum dwellers remains a persistent problem in Dhaka. A possible coping mechanism for women is home based work. This study aims to explore where, with whom, why and how women work in micro-scale work environments in slums of Dhaka. A brief background of the socio-spatial context of home based work in slums will be presented with a detailed description of the space typologies of home-based work environments.

\section{Research Methodology}

The existing studies focus on the need of home based work in terms of its capacity for direct livelihood support. There has been very little research and documentation on how home based work empowers women to cope with gender inequality in slums. In addition, there has been little research done in adaptive micro-scale work environments as a forum for the home based work from an architectural perspective. This is particularly critical in slums because of two issues: lack of adequate space and gender discrimination in terms of ownership of household spaces.

The study examines gender inequality and coping mechanisms adopted by female slum dwellers of Dhaka city through home based work. The study focuses on how micro scale adaptive home based work environments help in coping with gender inequality. After a pilot survey of several urban slums, Korail slum of Dhaka was selected as the case study area. The area has been developed and occupied by more than 18,000 poor households with no security of tenure. The areas were selected as it has a high concentration of female home-based workers with a strong social network and all the other critical components of an urban slum in central city.

Data was collected through a multi-method data collection approach consisting observation, photographs, questionnaire survey, household case history, informal interview supplemented with focus group discussions with female home-based workers of Korail. Purposive sampling was used for the study; the choice of which household units to include and exclude was theoretically-driven (households having 
active female home based workers). To obtain sufficient data that represent the population of Korail, care was taken so that the sample was not undersized. Access to the samples was not always easy as many female workers were reluctant to participate as they were working on encroached spaces. Ultimately about 35 households could be accessed. It should be noted that, for a qualitative survey, this was probably a saturation size as adding new data from a larger sample size would not have improved the findings.

To analyze the data, a qualitative interpretative approach was used. A schematic list of the stages in the development of grounded theory was modified and used as a guide. The aim was to identify adapted spaces and their role as coping mechanism in everyday life. Self-employed home-based workers as well as sub-contracted home-based workers were included. The survey with female home-based workers was supplemented by additional interviews with city officials, NGO and development workers.

The steps outlined here were followed reflexively according to the nature of the questions and data:

1. Using the available data to develop categories and types.

2. Defining the category or type by generally stating the criteria for later instances of using them.

3. Using the set of definitions as a guide to explore, identify, and explain the issues emerging from the field study.

4. Exploiting the types or categories, being aware of the possibility of additional types or categories emerging from the repetition of the process. This includes their opposites, and more specific and more general instances.

5. Developing links between types or categories. Exploring linkages and relationships among types or categories and try to develop matrices that show that relationships.

To make the research ethically sound, the following issues were strictly maintained:

1. Privacy and anonymity or respondents was maintained. No identifiable information and facts, especially quotations were used.

2. Each of the respondents participated voluntarily in the research.

3. There was no use of offensive, discriminatory, or other unacceptable language in the data collection process using questionnaire, household case history, informal interview and focus group discussions.

4. Where possible, the survey participants were asked to validate the conclusions made from their data.

5. Highest level of objectivity was maintained in discussions and analyses throughout the research.

The possible contributions of this study could lead to identifying the space typologies that help female slum dwellers earn their livelihood and in coping with gender inequality. Possible future contributions could include future urban expansion where these types of spaces can be integrated informally or formally. Data collected from the survey is primary. However, the study has the limitation of using secondary data to suggest various demographic and related trends. To gather data in such a large scale to form these trends was beyond the scope of this study.

\section{Gender Disparity in Slums}

Contemporary gender dynamics of cities shows a steady demographic process pertinent to women increasingly forming the majority of urban populations. Despite some narrowing of gender gaps in education in recent decades, women constitute approximately two-thirds of 774 million adult illiterates worldwide [12]. Amidst this, the complex assemblage of gender disparities requires a nuanced consideration of women's disadvantage from a multidimensional perspective, which takes into consideration the politics of space at different and interrelated scales from the household, to the neighborhood, to cities at large [13].

UN Millennium project (2002 to 2006) states in Target 4 under Goal 3 (Promote Gender Equality and Empower Women): "Eliminate gender disparity in primary and secondary education, preferably by 2005 , and in all levels of education no later than 2015" [14]. There are acute inequalities, gender discrimination and lack of women's basic rights in slums $[15,16]$. The root causes are lack of education and knowledge, poverty, ambiguous legal systems and lack of application, socio-cultural emphasis on the prerogatives of males and their blood relations, etc. In general, the greater society (including slums) has male bias in terms of inheritance and owning property. In addition, there are strong symbolic dimensions surrounding the 'forbidden' and 'permitted' use of spaces governed by patriarchal power relations and norms [17].

Gender gaps remain significant in urban labor markets in respect of the occupations in which women and men are engaged and on what basis, notably 'formal' or 'informal', part-time or full-time, and so on [18]. As shown in Figure 1, the most common gender disparities in slums happen due to women's limited access to stable employment and earnings, finance and credit. This discriminatory processes within the home and in the labor market to limit the type of income-generating options available to women as well as leading to a lower value being placed on 'women's work' [18]. 


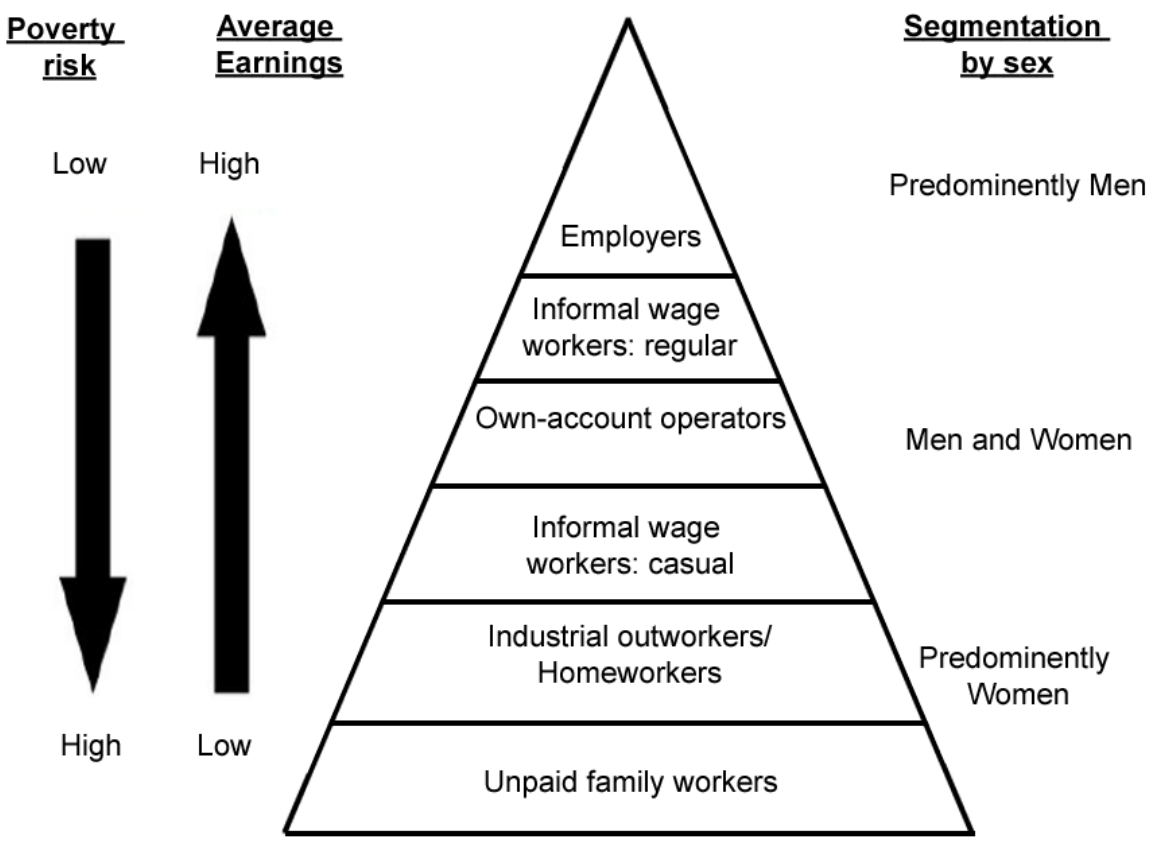

Figure 1. Segmentation by sex within informal economy, source: author, adapted from Chen et al [22].

Eviction and/or homelessness are common for female slum dwellers; which generally occurs in the event of divorce or desertion. Divorcees and widows become especially vulnerable; in dire circumstances, they can adapt various demeaning and immoral strategies such as prostitution for survival. Rehabilitation projects by government or NGOs are rather rare and the units are generally allotted to the head of household i.e. men. In slums, single women without male 'guardians' are automatically assumed to be of bad character. Due to this ill assumption, single women find it difficult to get accommodation even in slums. Field study shows that women mostly cope with this inequality and earn their place in society with home based work.

\section{Home Based Work and Space Usage}

In large cities, urban informal sector constitutes a significant part of economy. Informal sector businesses can take advantage of personal and domestic assets, such as living quarters, vehicles, and furniture which help them survive [19-20]. Yasmeen [21] stresses on the importance of urban informal sector in developing countries where population and demand for jobs, goods and services grows too quickly for the formal sector to cope with. It is a survival strategy as well, especially in many countries that have no effective social safety nets such as pension schemes, unemployment insurance, etc. Although men also work informally, women tend to fare worse on account of their restricted use of space, their lower levels of skills and work experience, limited access to start-up capital, and their underor un-paid roles in 'family enterprises' [22-23].

Female slum dwellers have been using home-based work and limited access to credit to achieve sustainable livelihood. Charmes [24] defines home based (also known as household or unincorporated) enterprises by their legal status and type of accounts that distinguishes them from formal corporations. Having no separate legal entities, they are independent of the household members that own them. They do not have a clear distinction between the production and other activities of their owners. When there is no or limited scope for formal wages HBEs help them survive.

Space is a fundamental resource in the operation of Home based enterprises (HBEs) and is considered a fungible asset, which makes the home a valuable place in which to carry out economic activities. Parochial spaces adjacent to homesteads are crucial for appropriation of productive resources for female slum dwellers. 'Home-based work' is a specific manifestation of female slum dweller's involvement in the household production-reproduction sphere in slums. This shows a sharp contrast with the existing studies on home-based work, in the South Asian cities, are usually confined within 'separate spheres' [25].

Field study suggests that space usage for home-based work is not spatially confined within dwellings. Ghafur [26] states, home based income generation takes place within a given dwelling and its broader physical context. Various related activities such as procuring raw materials, producing, marketing and selling products takes place in immediate parochial spaces to greater neighborhood. The advantages include little overhead cost, availability of household resources such as space and utility connections, self-sustaining and self-financing developments, the opportunity to trade off resources between domestic and productive activities, save time and money, as they do not 
need to travel. In addition, they can make effective use of social and human resources such as relatives/friends in exchange of small sums of money or benefits in kind; and especially it enables women to have productive work even in social conditions where their movement and social intercourse are restricted (See studies by [27-33]). Disadvantages include environmental degradation, endangering overstretched municipal services, fire hazards, increasing noise pollution and the risk of crime involved [31].

Rendell [34] observes that spaces are representational they embody complex symbolisms linked to underlying values. Home based work has a gender dimension that is socially constructed and socially reinforced; it decides who uses what space at what time and for what purpose. Home based work promotes self-employment opportunities and helps to establish a close work-home relationship [35]. The space typology where women work (open or enclosed, visible to outsiders or not) is defined by gender relations, religious and cultural ideologies (see Table 2). Hence, space embraces a multitude of intersections and can be defined through various power relations. In this respect home based work enterprises facilitate the female entrepreneurs to release their creative energy and earning potential, maintaining privacy, as reflected in the spacy typologies seen in the field study. This is often more agreeable with the local cultural and religious context.

Home based workers can be subdivided into two broad categories (see Figure 1): self-employed workers and sub-contracted workers. Of the two categories, the majority are subcontracted workers who work directly or through intermediaries, typically on a piece-rate basis. The distinction between self-employed and sub-contracted home based workers lies mainly in varying levels of decision-making power.

In most slums of Dhaka, home based work cuts across different branches of industry (see Table 2) and accounts for about one fourth of the urban informal employment. Some of these occupations are gender-specific. Female workers are mostly involved in cooking, stitching, making bamboo products, pottery, broom making while men commonly do traditional painting and woodcarving. Some occupations involve both women and men, but with each specializing at different stages of production (e.g., weaving by male workers and then embellishment of Jamdani sari by female workers).

Table 2. Different types of home based work by gender and spacerequired, source: author.

\begin{tabular}{|c|c|c|}
\hline Type of Home based work & Gender & Approximate space required (sqft/person) \\
\hline Traditional painting & Male & 15 \\
\hline Wood carving & Female & 50 \\
\hline Hand-stitching (Garment) & Male & 12 \\
\hline Handloom/weaving & Male/Female & 20 \\
\hline Tailoring/sewing (Garment) & Female & 15 \\
\hline Embellishment/ embroidery (Garment) & Female & 20 \\
\hline Chumky/Karchupi setting (sequins and jewellery) & Female & 25 \\
\hline Cooking & Male/Female & 60 \\
\hline Bamboo products & Male/Female & 18 \\
\hline Pottery & Male/Female & 15 \\
\hline Bgarbati-candle making & Female & 20 \\
\hline Bidi (local cigarette) rolling & Male/Female & \\
\hline
\end{tabular}



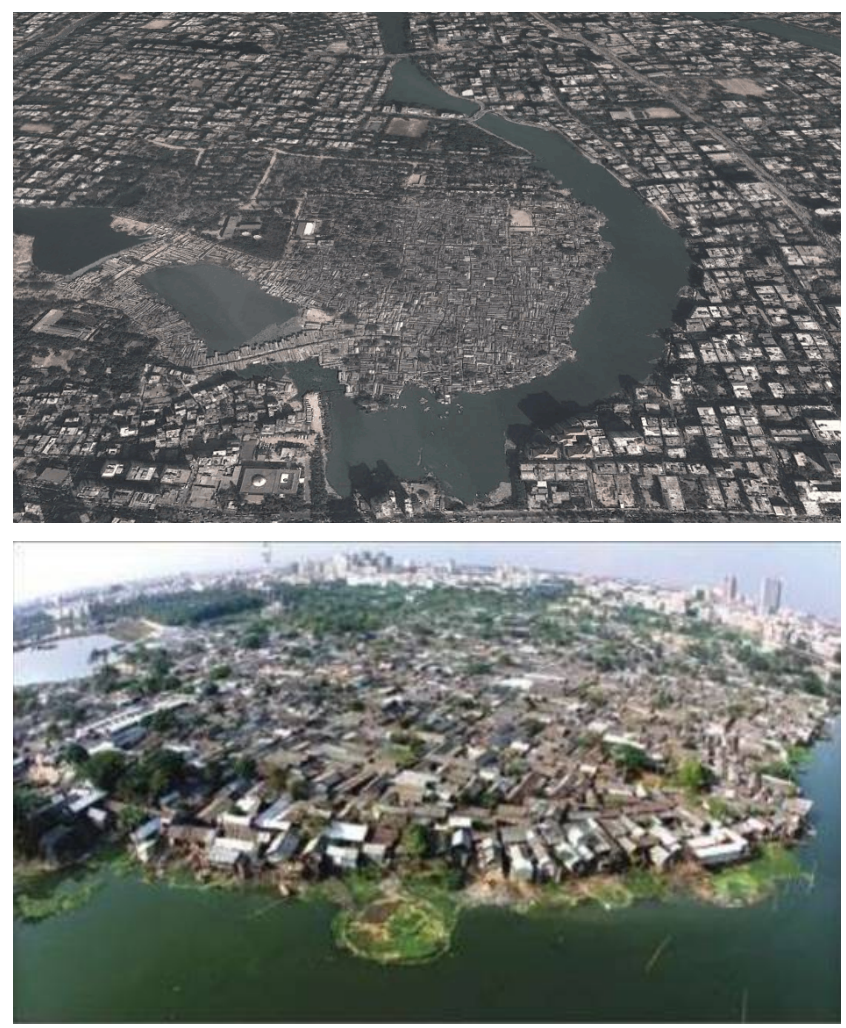

Figure 2. Aerial view of Korail slum, Dhaka, source: [36] and author.

The vast majority of home-based workers of Dhaka are women who face greater challenges when they want to start. The scope of home based work is greatly limited by overcrowding, lack of space, lack of financial assets, etc. Those who can overcome these obstacles and actually start home based work occupy the bottom links of value chains in most cases. They earn as little as they have to pay the overhead costs of production such as space, utilities and equipment. Some of the common problems faced by women are irregular work orders, arbitrary rejection of goods and delayed payments [28]. Home-based female workers have direct contact with the market and buy their own raw material facing competition from larger and more powerful formal businesses. They often do not have access to credit except at exorbitant rates of interests from local community sources. They lack bargaining power and social protection and remain largely invisible and voiceless. However, this scenario can partially improve if the overhead cost of renting a space can be substituted with a spontaneous micro scale adapted work environment.

\section{Adaptive Home Based Workspaces and Their Role in Coping with Gender Inequality}

Korail slum is one of the best examples of "pirate urbanism" [2] appearing near an important city center (Gulshan) enabled by local political support, bribes, etc. Use of the term pirate is apt here as the two phenomena occurred simultaneously here. First, the slum developed grabbing some of the most expensive land in the city right in front of the public eye; second, at later stages it developed by landfilling an important water body (GulshanLake) at the city center. Typical to the urban slums of the region, Korail has been growing with no administrative control, providing the dwellers with maximum freedom to build. Over the last four decades, spaces have been grabbed from Gulshan Lake, a prime water body at the center of an upscale residential area. The growth has been steady, gradually transforming the slum into a substantial area, blocking an entire part of the lake. In Korail, about $70-80 \%$ of the land is taken up for housing with maximum ground-coverage (Figure 2). The density is high, providing some of the cheapest and most affordable minimal shelters.

During the formative days in 1980 s, there was no infrastructure in Korail. Municipal services were gradually added during the next two decades as slum-dwellers constituted a sizable urban population. Korail has a vibrant community with a wide range of social and communal spaces and facilities. This ranges from parochial spaces at the doorstep, providing minimal space for social interaction to larger community gathering spaces for social activities.

The dwelling units are small, generally single storied with some having a second story. They are multi-functional, including spaces where family functions, interactions and work overlap to create some of the best optimized living spaces. As the slum dwellers occupy their units, the adjacent spaces, both towards the lake and in between the units are up for micro scale additions. These additions are not done overnight, it is a slow and gradual process. After a certain period, the spaces become their 'own'. However, they are smart enough not to invest too much in these spaces; the construction is temporary or semi-permanent in nature, often having only roof and minimum enclosure (Figure 3,4, 5 and 7). 

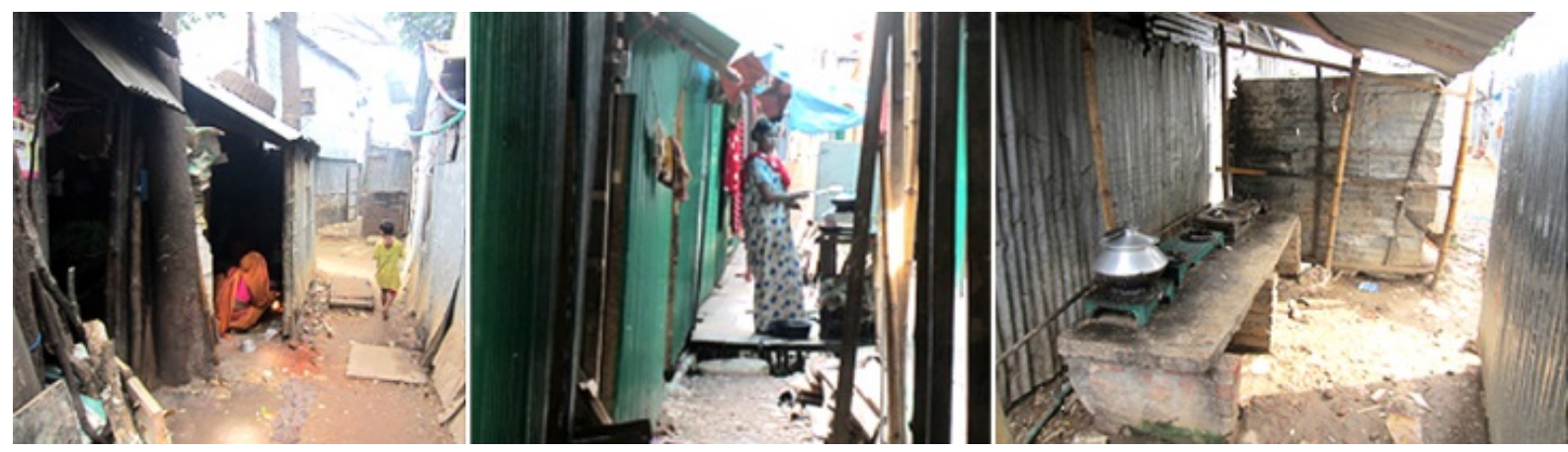

Figure 3. Home based female workers cooking in micro scale adaptive work environments, source: author
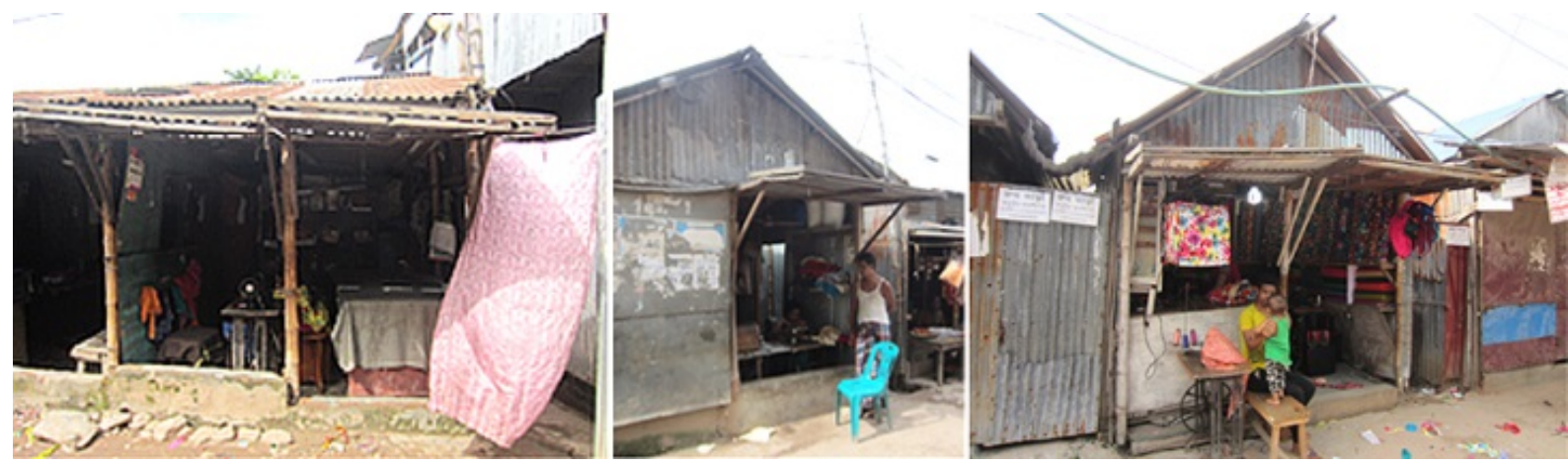

Figure 4. Home based female workers sewing in micro scale adaptive work environments, source: author
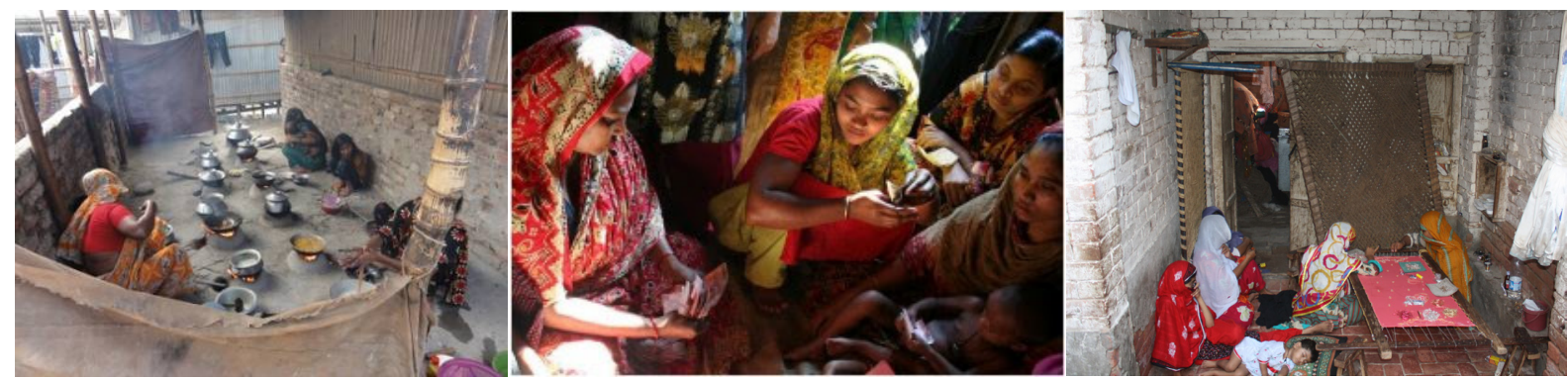

Figure 5. Home based female workers in micro scale adaptive work environments, source: author

Figure 3 shows three cases where female home based workers are involved in cooking and supplying lunch for office workers in the city. All three cases are corridor type adapted workspaces as shown in Figure 8. In the first two cases, the space created for cooking is very primary. The female worker shown in the left has encroached a little to the corridor beside her home and created partial enclosure around her workspace with recycled tin. Comparatively, the female worker shown in the middle barely encroached the corridor beside her home; rather she created a basic partition just to accommodate a burner where she cooks standing. The workspace shown in the right is of secondary nature where the female worker has spent enough years in the business to gain confidence to create a better workspace. Here she strategically used the bend of a public corridor where the space is relatively wider and has placed five burners to run her business at a larger capacity.

Figure 4 shows three cases where female home based workers are involved in various forms of tailoring, sewing, embellishment, embroidery, Chumky-Karchupi setting (sequins and jewellery) in garments. The workspace of the female home based worker shown in the left is of primary nature. Here, she recently started her business using an extended space beside her home as shown in Figure 8 semi-open veranda type. Due to the tentative nature of her business, there is no formal partition in the shop-front, and the flat roof is made with recycled tin. Comparatively, the two cases shown in the middle and right have better partitions and roofs than the first case. The female workers here have spent more years in the business and have gradually made the encroached spaces their 'own'.

The female home based workers work in dwellings that are small and crowded with little or no infrastructure, water connection, drainage, sanitation, light and ventilation. They in turn affect productivity. They are also vulnerable to frequent evictions and insecurity of tenure. Spaces are overcrowded and require constant reorganization for different activities. Amidst these realities, they find an 
'escape' in the form of micro scale work places, often in the form of an extension and alteration of the main house. In most cases, the micro scale adaptive spaces were not originally part of the household. Serendipitously they become a part of the household and in time become inseparable corners of home based work. They are invariably partial, provisional, and often experimental. However, economic conditions greatly influence the decision of materials and types of construction. These spaces display indigenous creativity of design, spatial and social adaptation. It supports the idea that poverty of resources does not have to result in poverty of imagination.

Three basic types of micro-scale adapted work spaces are shown in Figure 8 with activity zones highlighted. Depending on whether they are open air (corridor type), semi-open (veranda type) or composite (courtyard type), home based works vary significantly. Open air activities such as traditional painting, handloom/weaving, cooking requires semi-open or covered spaces while activities such as pottery requires both covered and open spaces, i.e. composite type.

Figure 6 shows the transformation stages of home based work spaces and their hierarchy from private to public spaces. The first stage adaptation takes place in an intimate parochial zone. Here the intervention is minimum, investment low and activity limited. The second stage adaptation takes place in threshold between parochial and public space. Here the intervention is moderate, investment medium with a wider range of activities. The third stage adaptation encroaches public space. Here the intervention is in public space, with greater influence, investment and activities.

Three cluster types and the encroachments that take place in stages are shown in Figure 9. The first stage additions generally extend or connect the most private part of the dwelling with parochial spaces where the public access remains unharmed. This stage generally facilitates establishment of home based businesses. Once businesses start to prosper, more space is required, leading to stage 2 of the encroachment. Here spaces that are more public are grabbed. As cluster type 1 and 2 shows, stage 2 development has significantly narrowed the public access. This is even more dire in cluster type 3 where the public access is entirely blocked (Figure 9). This type of encroachment happens where the dwellers have a greater level of social influence.

The flexibility to build incrementally within adjacent spaces of the dwelling units is closely related to the semi-permanent nature of the dwelling units. They are built with locally available materials such as new and used corrugated iron and tin sheets, timber rafters, country tiles, joists and posts, plastic sheets and other recycled materials. The extended micro-scale workspaces mostly use recycled materials such as used corrugated iron sheets, light bamboo fences, etc.

In struggling economic conditions, home based enterprises of Korail help in survival by adding to average household income, even though the space they take is illegally occupied. They contribute to the general welfare of the local neighborhoods through positive activities as oppose to anti-social activities. Women's participation in the labor force is pivotal for survival of most households. Despite scarce resources, women take on productive roles as well as engaging in community with micro-scale workspaces as their stage. One female home based worker shared, "we were struggling with only my husband's income, after I started cooking and supplying lunch from this little space beside my home, our economic condition has significantly improved".

An additional contribution is the social security of woman through economic freedom as they gain a better status in the household. A female worker observed, "my position in the family has improved after I prepared this space and started making bamboo products with the help of my children; now I can contribute to the household expenses and my opinion is taken seriously". For women living in slums who otherwise would have been unemployed, home based work provides not only means of survival but also a much-needed hope. It restores the power balance, albeit partially. Even though social security is minimum; finance and institutional support(often from NGOs) gradually becomes available when the home based businesses have some kind of physical existence in the micro-scale spaces. 


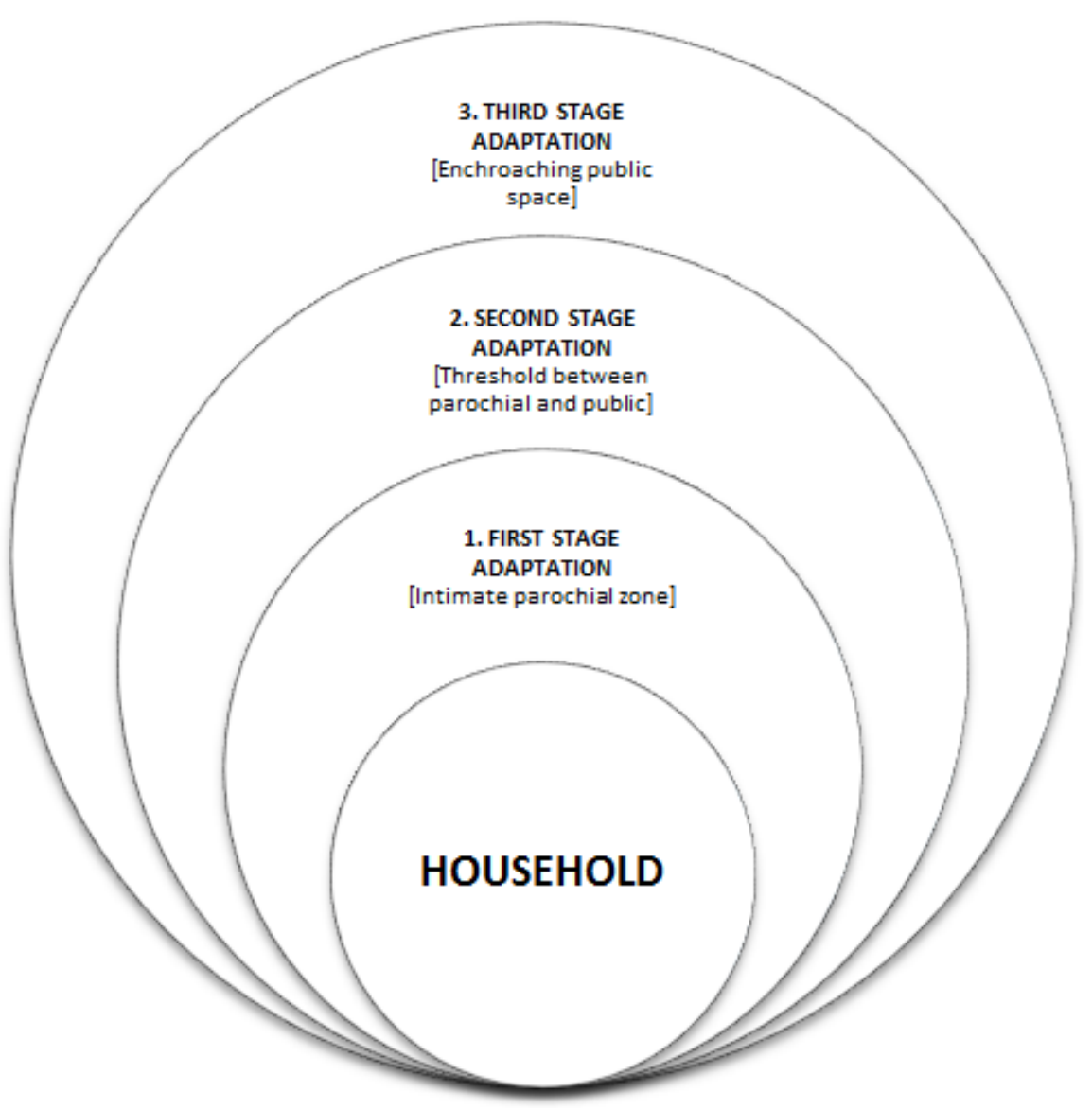

1. Least intervention, low investment, limited activity.

\section{Moderate} intervention, medium investment, wider range of activities.

3. Nearly intervening public space, greater influence, investment and activities.

Figure 6. Transformation stages of home based work spaces from private to public, source: author.

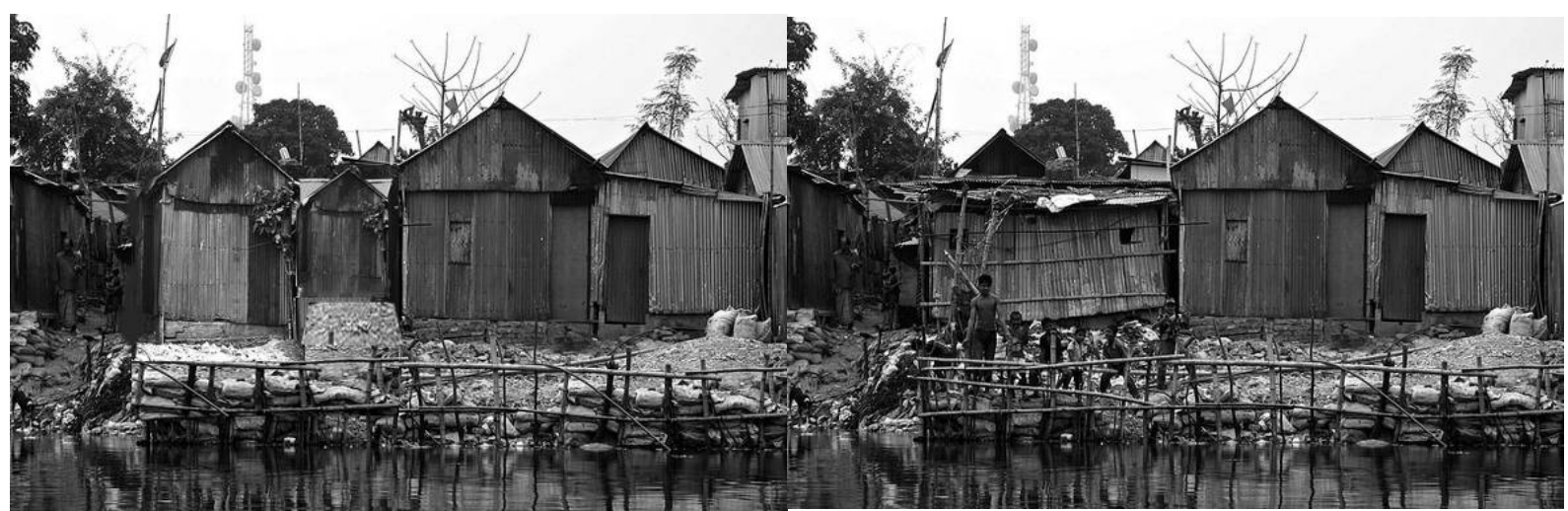

Figure 7. A housing cluster at Korail slum, left - before and right - after addition of micro scale work spaces, source: author 


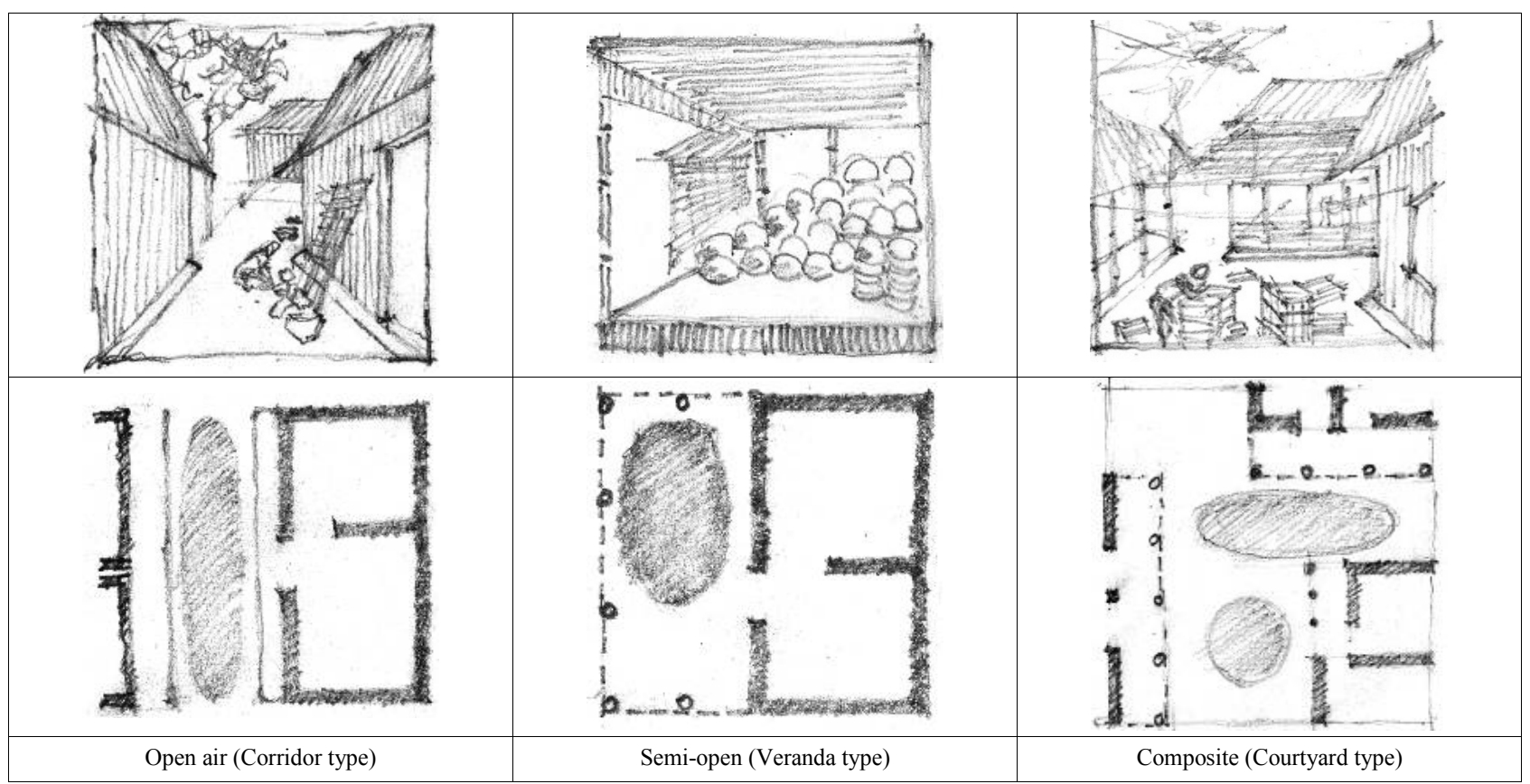

Figure 8. Basic typology of micro scale adaptive work environments at Korail slum, source: author

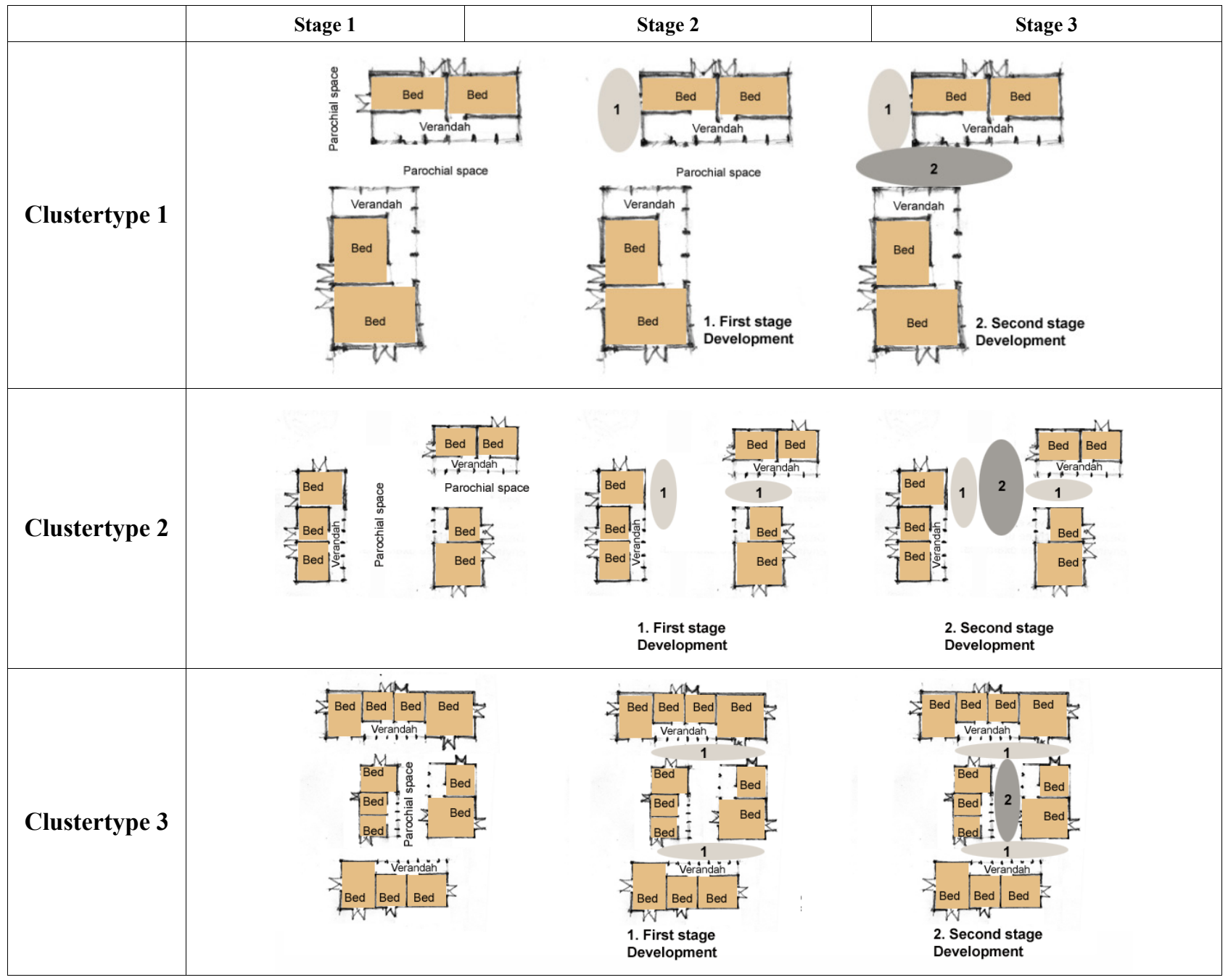

Figure 9. Different housing cluster types and developmental stages of micro scale adaptive work environments at Korail slum, source: author 
The study shows that adapted micro-scale spaces are not gender biased, the households require no extra resource and there is no conflict between established gender norms and emerging needs in the households. This presents a new spatial practice where women find their economic and social space, keeping the gender dynamics, which, in turn, influences and alters social processes as well. In the long run this spatial practice and adaptive capacity of individuals within a house or a neighborhood enables women to cope with gender inequality.

\section{Recommendations}

Female slum dwellers of Korail face difficult and complex socioeconomic challenges. The study shows that they have a spontaneous ability for cultural adaptations and creating home-work environments as survival strategies which can guide future interventions. The challenge remains for city managers to use this urban phenomenon (micro scale work environments) positively, gradually making them a part of the system.

Several NGOs have been working in slums such as Korail. The female workers could do better with external support. NGO or similar bodies' role could be to support the female workers acting as facilitators to bridge the gaps between the overall slum communities and struggling female workers. Support can come in the form of small scale improvements (aided by local initiatives) which may inspire others and more comprehensive upgrades where female workers can join micro scale spaces into larger entities where space and work can consolidate. This has the potential to influence and improve employment infrastructures for female workers in slums significantly. However, any support should consider the real social, economic and financial challenges and it should enable community action.

Empowering the under-skilled and poorly trained female workers is vital. Existing resources (skills, experience, space, etc.) may be minimal but these should be strategically used to support them through active participation in decision-making. This in turn could inspire gradual change in social and economic capital. The micro scale work spaces provide a strong cue to what approach should be taken by the NGOs or government. Then the solution will be place specific and appropriate.

\section{Conclusions}

There is a deep rooted gender bias in society in the form of social, cultural, economic, legal and political discrimination to women. The study shows how provision of physical spaces for work helps them cope with the discrimination. Considering numerous infrastructural, economic, environmental, and social failures of recent urban policies in recent years; the possible initiatives from stakeholders (such as NGOs, industry, academic and research institutions, international organizations, etc.) can contribute in their small way as a solution to social and spatial inequalities in slums. These adapted home based work spaces create a stage where future institutional input, infrastructure development and possible stakeholders' support may become possible. There is no set of best practices for this and it is open to interpretation.

It would be impractical to think of eradicating settlements such as Korail as they are too large and their populous makes an important contribution to urban economy; especially since sufficient vacant land to relocate them is scarce in Dhaka. Leaving the slums where they are may initially seem cumbersome and arguably more expensive, but relocation has often led to gentrification. Also, developing infrastructure has the advantage of leaving the local economic and social networks intact, supporting local initiatives which could be a possible way forward. A whole new vision is required to sustain this existing phenomenon (female slum dwellers coping spontaneously) for a more humane home-work environment in slums.

\section{REFERENCES}

[1] B. Dahiya. Cities in Asia, 2012: Demographics, economics, poverty, environment and governance. Cities, Vol. 29, 44-61, 2012.

[2] C. Werthmann, J. Beardsley, Improving Informal Settlements: Ideas from Latin America. Harvard Design Magazine, Vol. 28, 31-34, 2008.

[3] WPR. Bangladesh Population 2015, Online available from http://worldpopulationreview.com/countries/bangladesh-popu lation/. 2016.

[4] IMF, Bangladesh: Poverty Reduction Strategy Paper. Asia and Pacific Dept: International Monetary Fund. 206, 2013

[5] M.K. Roy, G.C. Sarker, Rural and urban Migration: The Role of Secondary Cities (Report), in the daily Bangladesh observer. 2006.

[6] bdnews24.com. Bangladesh's per capita income rises to \$1,314. 201514 May 28 August, 2016]; Online available from

http://bdnews24.com/economy/2015/05/14/bangladeshs-per-c apita-income-rises-to-1314.

[7] Indexmundi. Bangladesh Demographics Profile 2014. 2015 June $30 \quad 28$ August, 2016]; Online available from http://www.indexmundi.com/bangladesh/demographics_profi le.html.

[8] BBS, Preliminary report on Census of slum areas and floating population 2014, Bangladesh Bureau of Statistics, Dhaka, 2015.

[9] Worldometers. Bangladesh Population (1950 - 2016). 2016 27 August, 2016]; Online available from http://www.worldometers.info/world-population/bangladeshpopulation/. 
[10] Millenniumgoals. Millennium Development Goals and beyond 2015. 201325 September 28 August, 2016]; Online available from

http://www.un.org/millenniumgoals/environ.shtml.

[11] UHNBD. Rapid Urbanizations and the Women in the Slums in Dhaka City. 201428 August, 2016]; Online available from http://www.uhnbd.net/index.php/resources/buhnarticles/16-rapid-urbanizations-and-the-women-in-the-slums-i n-dhaka-city.

[12] United Nations Department for Economic and Social Affairs (UN-DESA) the World's Women 2010: Trends and Statistics (New York: UN). Vol. 43, 2010.

[13] S. Chant, D. Kerwin, Women in Cities: Prosperity or Poverty? The Importance of Multidimensional and Multi-Spatial Analysis. Paper presented at, 'The City in Urban Poverty' workshop, DPU, University College London, 10-11 November, 2011.

[14] UNMillenniumproject.Goals, targets and indicators. 200628 August, 2016]; Available from: http://www.unmillenniumproject.org/goals/gti.htm.

[15] UN. Convention on the elimination of all forms of discrimination against women. 200928 August, 2016]; Online available from

http://www.un.org/womenwatch/daw/cedaw/.

[16] L. McDowell, Gender, Identity and Place: Understanding Feminist Geographies. Minneapolis: University of Minnesota Press, 1999.

[17] S. Chant, C. McIlwaine, 2013, Gender, urban development and the politics of space. E-International Relations. $<$ http://www.e-ir.info/2013/06/04/gender-urban-development-a nd-the-politics-of-space/>(accessed April 18, 2015).

[18] D. Elson, 'Labour Markets as Gendered Institutions: Equality, Efficiency and Empowerment Issues', World Development, Vol. 27, No. 3, 611-27, 1999.

[19] M. P. Todaro. A model of labor migration and urban unemployment in less developed countries. American Economic Review, Vol 59, No. 1, 138-148, 1969.

[20] A. Gilbert. Home enterprises in poor urban settlements: constraints, potentials and policy options. Regional Development Dialogue, Vol. 9, No. 4, 21-37, 1988.

[21] G. Yasmeen. Stockbrokers turned sandwich vendors: the economic crisis and small scale food retailing in South East Asia. Geoforum, Vol. 32, No. 1, 91-102, 2001.

[22] M. A. Chen, M. Carr, J. Vanek. Mainstreaming Informal Employment and Gender in Poverty Reduction: A Handbook for Policymakers and Other Stakeholders, Commonwealth Secretariat, London, 2004.
[23] S. Henry. The Hidden Economy, Martin Robertson, London, 1978.

[24] J. Charmes. Informal Sector, Poverty, and Gender: A Review of Empirical Evidence, in World Development Report. World Bank, Washington D.C., 2000.

[25] S. C. White. Women and development:A new imperialist discourse. The Journal of Social Studies, Vol. 48, 90-111, 1990.

[26] S. Ghafur. Beyond Homemaking: The role of slum improvement in home based income generation in Bangladesh Third world Planning review, Vol. 23, No. 2, 111-135, 2001.

[27] M. Mehta. Home Upgradation and Income generation from housing, in Housing and Income in the Third world urban development, D. Raj and P. Nientied, Editors, Aspect Publishing: London. 129-140, 1990.

[28] E. Boris, E. Prügl, eds. Homeworkers in Global Perspective: Invisible No More, Routledge, New York, 1996.

[29] V. Singh, G. Kowale, Employment Conditions, exploitation, safety, and income in home based enterprises in Brassware industry of Aligarh, in International conference on housing, work and development: the role of home based enterprises. University of Newcastle upon Tyne, 2000.

[30] T. Lawanson, D. Olanrewaju, The Home as Workplace: Investigating Home Based Enterprises in Low Income Settlements of the Lagos Metropolis, in 48h ISOCARP Congress. 2012

[31] K. Ogunbunmi. Urban Stories: A tale of three cities: Karachi, Kingston and Lagos. In Focus 200528 August 2016]; Available from: www.povertycentre-undp.org.retrievedon.

[32] T. Fenster. The Right to the Gendered City: Different Formations of Belonging in Everyday Life. Journal of Gender Studies, Vol. 14, No. 3, 217-31, 2005.

[33] D. Massey. Space, Place and Gender, University of Minnesota Press, Minneapolis, 1994.

[34] J. Rendell. "Introduction: Gender, space", in J Rendell, B Penner and I Borden (editors), Gender Space Architecture: An Interdisciplinary Introduction, Routledge, London, 103, 2000 .

[35] T. Lawanson, D. Olanrewaju, The Home as Workplace: Investigating Home Based Enterprises in Low Income Settlements of the Lagos Metropolis, in $48 \mathrm{~h}$ ISOCARP Congress. 2012.

[36] Google Earth (Version 5.1.3533.1731) [Software]. Mountain View, CA: Google Inc. (2009). Available from http://too.lazy.to.look.it.up/ 